\title{
Pharmacogenetics of uridine diphosphate glucuronosyltransferase (UGT2B7) genetic polymorphism on valproic acid pharmacokinetics in epilepsy
}

Murali Munisamy ${ }^{1 *}$, Gauthaman Karunakaran², Mubarak Al-Gahtany ${ }^{3}$, Vivekanandhan Subbiah ${ }^{4}$, Manjari M Tripathi ${ }^{4}$

From 2nd International Genomic Medical Conference (IGMC 2013)

Jeddah, Kingdom of Saudi Arabia. 24-27 November 2013

\section{Background}

Sodium valproate is a widely prescribed broad-spectrum antiepileptic drug. It shows high inter-individual variability in pharmacokinetics and pharmacodynamics and has a narrow therapeutic range [1]. We evaluated the effects of polymorphic Uridine diphosphate glucuronosyltransferase (UGT2B7) metabolizing enzyme on the pharmacokinetics of sodium valproate in the patients with epilepsy who showed toxicity to therapy.

\section{Materials and methods}

Genotype analysis of the patients was made with polymerase chain-restriction fragment length polymorphism (RFLP) with sequencing. Plasma drug concentrations were measured with reversed phase high-performance liquid chromatography (HPLC) and concentration-time data were analyzed by using a non-compartmental approach.

\section{Results}

The results of this study suggested a significant genotypic as well as allelic association with valproic acid toxicity for UGT2B7 polymorphic enzymes. The elimination half-life $\left(\mathrm{t}_{1 / 2}=42.2 \mathrm{~h}\right)$ of valproic acid was longer and the clearance rate $(\mathrm{CL}=947 \mathrm{ml} / \mathrm{h})$ was lower in the poor metabolizers group of UGT2B7 polymorphism who showed toxicity than in the intermediate metabolizers group $(\mathrm{t} 1 / 2=36.5 \mathrm{~h}$, $\mathrm{CL}=1,042 \mathrm{ml} / \mathrm{h}$ ) or the extensive metabolizers group $(\mathrm{t} 1 / 2=27 . \mathrm{h}, \mathrm{CL}=1,602 \mathrm{ml} / \mathrm{h})$.

\section{Conclusions}

Our findings suggest that the UGT2B7 genetic polymorphism plays a significant role in the steady state concentration of valproic acid, and it thereby has an impact on the toxicity of the valproic acid used in the patients with epilepsy.

\section{Authors' details}

'Department of Pharmaceutics, College of Pharmacy, King Khalid, University, Abha, Saudi Arabia. ${ }^{2}$ Department of Pharmacology, College of Pharmacy, King Khalid University, Abha, Saudi Arabia. ${ }^{3}$ Faculty of Neuro Surgery, King Khalid University, Abha, Saudi Arabia. ${ }^{4}$ Neurosciences Centre, All India Institute of Medical Sciences, New Delhi, India.

Published: 2 April 2014

Reference

1. Chu XM, Zhang LF, Wang GJ, Zhang SN, Zhou JH, Hao HP: Influence of UDP- glucuronosyltransferase polymorphisms on valproic acid pharmacokinetics in Chinese epilepsy patients. Eur J Clin Pharmacol 2012, 68(10):1395-401

doi:10.1186/1471-2164-15-S2-P3

Cite this article as: Munisamy et al.: Pharmacogenetics of uridine diphosphate glucuronosyltransferase (UGT2B7) genetic polymorphism on valproic acid pharmacokinetics in epilepsy. BMC Genomics 2014 15(Suppl 2):P3.

\footnotetext{
* Correspondence: muralimunisamy@gmail.com

'Department of Pharmaceutics, College of Pharmacy, King Khalid, University, Abha, Saudi Arabia

Full list of author information is available at the end of the article
} 